\title{
ДИАЛОГ КУЛЬТУР
}

\author{
С.Б. Никонова
}

\section{К ФИЛОСОФИИ ДИАЛОГА КУЛЬТУР. ПО МАТЕРИАЛАМ ХІV МЕЖДУНАРОДНЫХ ЛИХАЧЁВСКИХ НАУЧНЫХ ЧТЕНИЙ}

\begin{abstract}
Аннотация. В статье рассматриваются проблемы, связанные с идеей диалога культур в современном мире. Эти проблемы связываются автором с происхождением идеи диалога культур из недр новоевропейского индивидуализма и субъективистской концепции познания. Западноевропейский способ мышления характеризуется как чреватый внутренними противоречиями. Развитие в его рамках гуманистического идеала отношения к человеку и признания ценности уникальной человеческой личности по структурным условиям своего формирования имеет в нем обратной стороной обезличивание, дегуманизацию и насилие. На основании ряда докладов, представленных на ХIV Международных Лихачёвских научных чтениях, даётся обзор различных позиций по отношению к возможности диалога культур. Анализируется изменение взглядов на диалог культур в связи с нарастанием напряженности в современном обществе, а также рассматриваются мировоззренческие основания конфликтогенности современной ситуации. В итоге вопрос о возможности диалога культур в современном мире оставляется как открытая возможность, что обусловливает крайнюю актуальность продолжающейся философской дискуссии на эту тему.

Ключевые слова: диалог, культура, противоречие, диалектика, конфликт, западноевропейский культурный проект, субъективизм, гуманизм, Я и Другой, секуляризация.

Review. In her article Nikonova discusses the problems associated with the idea of the dialogue of cultures in the modern world. These problems are associated with the origin of the idea of the dialogue of cultures from the foundations of modern European individualism and subjectivist conception of cognition. Western European way of thinking is characterized by internal contradictions. According to the author, development of the humanistic ideal and recognizing the value of a unique human being according to the structural conditions of its formation have depersonalization, dehumanization and violence as its reverse side. On the basis of a number of papers presented at the XIV International Likhachev Scientific Conference, an overview of the different positions in relation to the possibility of the dialogue between cultures is provided. The author analyzes the changing views on the dialogue of cultures in the light of the growing tension in modern society, and also examines the philosophical foundation of the current situation. As a result, the dialogue of cultures in the modern world is shown as the possibility that is still to be opened which causes the extreme urgency of the ongoing philosophical debate on this topic.
\end{abstract}

Keywords: dialectic, subjectivism, New European cultural project, Me and the Other, culture, conflict, contradiction, humanism, dialogue, secularization.

\section{Лихачёвские научные чтения в Санкт-Петербургском Гуманитарном университете профсоюзов}

В Санкт-Петербургском Гуманитарном университете профсоюзов ежегодно проходит большой международный форум, собирающий представителей научной, художественной, а также политической элиты, посвященный проблеме взаимодействия культур в современном мире. Из года в год тема фо- рума остается, с небольшими вариациями, одной и той же: «Диалог культур и партнерство цивилизаций». Такой акцент связан с тем, что проведение форума посвящено памяти и наследию отечественного ученого и мыслителя Д.С. Лихачёва, для которого именно диалогическое решение проблемы межкультурного взаимодействия представляло собой значимость. Следуя призывам этого искреннего гуманиста, гости форума пытаются осмыслить происходящие процессы во всей их сложности и много- 


\section{Философия и культура 6(90) • 2015}

образии. Обсуждаются и прикладные проблемы, приводятся конкретные примеры диалогических взаимодействий в сфере экономики, политики, науки, искусства. Также приводятся и примеры радикальных неразрешимых противостояний.

Актуальность происходящей в рамках Чтений дискуссии признается на государственном уровне, поскольку после ухода из жизни Д.С. Лихачёва, Указом Президента РФ В.В. Путина «Об увековечении памяти Д.С. Лихачёва» № 587 от 23 мая 2001 г. этому форуму придан государственный статус «Международных Лихачёвских научных чтений». Ежегодно президент России приветствует собирающихся на форум гостей, тем высоко оценивая значимость рассматриваемых вопросов и предлагаемых подходов. В 2014 г. при реализации проекта «XIV Международные Лихачёвские научные чтения» используются средства государственной поддержки, выделенные в качестве гранта Общероссийской общественной организацией «Общество “Знание” России» в соответствии с распоряжением Президента Российской Федерации от 29 марта 2013 г. № 115-рп.

Осенью 2014 г. издательством СПбГУП был выпущен в свет сборник докладов и материалов дискуссий XIV Международных Лихачёвских научных чтений (на русском и английском языках), состоявшихся 15-20 мая 2014 г. в Санкт-Петербургском Гуманитарном университете профсоюзов ${ }^{1}$.

\section{Проблема диалога культур и философия}

Условия современности, в которой обнаруживают себя люди той или иной эпохи, сами собой указывают на проблемы, обладающие неустранимой актуальностью, настаивающие на непрерывном обсуждении ввиду их насущности и упрямой неразрешимости. Возможность взаимодействия, сосуществования и сотрудничества разных культурных традиций, сталкивающихся в пространстве глобализирующегося мира, является одной из таких проблем, обладающих крайней значимостью в настоящее время. Причем с развитием событий эта значимость только нарастает, актуальность обо-

\footnotetext{
1 Диалог культур и партнерство цивилизаций: XIV Международные Лихачёвские научные чтения, 15-20 мая 2014 г. / Науч. ред. А.С. Запесоцкий. СПб.: СПбГУП, 2014. 592 с. Dialogue of Cultures and Partnership of Civilizations: the 14th International Likhachov Scientific Conference, May 15-20, 2014. / Ed. A.S. Zapesotsky. St. Petersburg: SPbUHSS, 2014. 174 p.
}

стряется, выявляются все новые грани, причем, если можно так сказать, грани весьма острые и часто болезненно ранящие. Ранее выдвинутые гипотезы терпят крах, а проблема остается по-прежнему даже не приблизившейся к разрешению. Ситуация меняется, и кажется, что иные из изменений, происходящих буквально у нас на глазах, рушат многие надежды, взлелеянные в прежних теориях, требуя новых подходов и радикальных переосмыслений. Возможно мы еще не дошли до понимания оснований проблемы, хоть они часто и представляются очевидными. А потому мы не можем еще до конца понять и того, что происходит на поверхности. Чтото всегда закрывает наши глаза, не давая увидеть сокровенной тайны совершающегося. Когда они откроются - кто знает, что будет? Так и античность не знала, что, возможно, всеми силами искала божественный источник истины за пределами мира, а когда он приоткрылся, была полностью и жестоко сметена его светом с лица земли. Решение проблемы, находимое неумолимостью истории, не всегда оказывается столь ясным, благостным и умиротворенным, как то представлялось грезящим о нем предшественникам. Потому необходимо как можно более всесторонне и тщательно обсуждать насущную проблему, как можно более непредвзято и смело углубляться в её корни, даже если есть опасность найти там нечто весьма нелицеприятное. Таковой всегда и была задача философии - раскрытие оснований, разбирание, демонтаж всего, казалось бы, надежного, чтобы найти то, на чем все это надежное держится. Со странным и все возрастающим риском в итоге не найти там внутри вообще никакой опоры. Тогда, возможно, здание, казавшееся выстроенным на века, рухнет как карточный домик. Но будет ли это большой утратой, если его видимость заставляла пребывать в безмятежности над зияющей бездной?

В этой переоценке ценностей преуспели некогда ещё первые постгегельянские философы, такие как Маркс, Шопенгауэр, Кьеркегор, и более всех - Ницше, призывающий «жертвовать истине всякими желаниями - каждой истине, даже простой, горькой, безобразной, отвратительной, нехристианской, неморальной истине... Ибо есть ведь и такие истины» ${ }^{2}$. Они заговорили о необходимости подобного демонтажа, углубления в подобную «герменевтику подозрения». По направлению к со-

Ницше Ф. К генеалогии морали / Пер. с нем. К.А. Свасьяна // Ницше Ф. Соч. в 2 т. М., 1990. Т. 2. С. 416. 
временности эта тенденция в философском анализе все увеличивается, а парадоксов и нестыковок, находимых в основаниях, становится все больше. Если только иметь смелость додумать до конца может оказаться что то, что представлялось очевидным, пустая иллюзия, и даже логическая ошибка. Но в контексте нашей проблемы возможно на этой функции и этой тенденции в философии и не стоило бы так подробно останавливаться, если бы удивительным образом она не соответствовала в своем развитии ходу тех самых глобализационных процессов и нарастанию проблем, связанных со взаимодействием культур. Процитированная выше работа «К генеалогии морали» является знаковой в осознании взаимосвязи этих процессов. Она подвергает критике поиск метафизических и над-человеческих основ ценностей и переводит поиск их формирования на историческую почву, заведомо указывая на диссонанс и противоречивость условий. То, что, по Ницше, существует «мораль господ» и «мораль рабов» не значит отнюдь, что этот схематизм имеет универсальную природу. Скорее следует это проинтерепретировать так, что источники ценностей являются внутричеловеческими, завязанными на конкретных отношениях, и даже, можно сказать, ситуативными, а общности в них ровно столько, сколько в людях общих пороков - корысти, алчности, эгоизма, жестокости, мстительности, недомыслия, тщеславия, трусости и слабости, а также грубой силы. Пропорция этих качеств порождает уникальные системы культуры тех или иных народов, неповторимые и восхитительные иерархии ценностей. Вот это и есть жизнь, которую он восприветствовал в своей философии с «трагическим оптимизмом» - феерия многообразия жизни. Но это производит еще одно важное для нас в нашем контексте действие: переводит философский поиск из метафизического в культурологический план. Теперь основания принципов и действий стоит искать не столько в фундаментальных условиях человеческого бытия вообще, но в преломлении их в той или иной культурно-исторической ситуации. Это преломление и даёт нам особые типы мироощущений и мировоззрений, рождающие различия между культурами.

\section{Диалог культур в современном мире: смена видения}

Если обратиться к архивам сборников Лихачёвских чтений за прошедшие годы, то можно увидеть до- статочно сильное изменение в оценке проблемы взаимодействия культур, которое происходит возможно подспудно, даже помимо желания участников, ввиду меняющейся ситуации в мире.

Но начнем с изменения, сильно предшествовавшего их началу. Однажды, когда мир перестал быть разделенным на два лагеря, и закончилась, по крайней мере, так стало казаться, холодная война между капитализмом и социализмом, это наполнило сознания людей, причем вероятно всех стран, в большинстве своем, неимоверным энтузиазмом. Вот тогда и стала актуальной наконец проблема не противостояния, не конфликта, а именно диалога культур. И такой диалог, плодотворное сотрудничество и взаимодействие, стали казаться в высшей степени возможными. Эта идея развивалась активно в западных странах, и она же вдохновляла и отечественные умы. Люди устали от напряжения, они хотели мира и солидарности. Общечеловеческие ценности, естественные права казались незыблемыми, а достижение соблюдения их - желанным. Но вот настали годы относительного, хотя бы видимого покоя, и оказалось, что этот покой рождает новое напряжение. Что враги и противники диалога и сотрудничества по-прежнему не дремлют - только они стали более коварными и менее определёнными. Теперь они не делят больше мир на две системы и не ведут непрерывную гонку вооружений. Но они, к примеру, устраивают теракты, точечные и непредсказуемые, со всегда не до конца понятными причинами и целями. Кто это? Может быть это представители другой культуры, скажем, исламисты, желающие установления своего порядка и возмущенные вторжением глобального мира в свои традиции? А, может быть, спор традиций здесь не при чем, а налицо действие экономических и политических интересов? Может, эти наводящие панику на простое несведущее население действия - плод каких-то экономических манипуляций? Может быть, за террористами стоят вовсе не исламистские, а совсем иные структуры, может быть, даже сами государственные службы на вид миролюбивых и готовых к диалогу стран провоцируют так общественные кризисы для своей хитрой политической игры? Рождаются многочисленные «теории заговора», где кто только ни выступает ключевыми фигурами и ни несет ответственности за нарушения порядка в мире. А может быть дело в том, что в отсутствие определённого врага хоть в каком-то враге возникает насущная необходимость? Просто в фигуре врага - чужого, другого, 


\section{Философия и культура 6(90) • 2015}

неведомого и опасного, с которым диалог невозможен, но который является виновником того, что порядок и мир до сих пор не достигнуты. Однажды такой поиск врага, актуализировавшись, привел и к возникновению немецкого национал-социализма. Какого расцвета, живости и бодрости достигла в этот момент немецкая нация - на фоне мрачного ужаса Холокоста, чтобы погрузиться через несколько лет в гибельную пучину Второй мировой войны! И вот те же националистические, фашистские настроения начинают актуализироваться теперь с новой силой во всех уголках мира, нагнетая обстановку и разделяя людей вновь на противоборствующие лагеря.

В любом случае, уже в ходе этих лет относительного «мира», довольно напряженного, сопряжённого с ростом панических настроений, многократно критикуемого за кажущиеся в высшей степени негативными трансформации, которые претерпевают культуры всех возможных стран (причем критика звучит часто с совершенно противоположных сторон), «мира», сопровождающегося непрерывным громыханием военных орудий, выявилось столько сложностей в налаживании сотрудничества и диалога между культурами, столько нюансов и аспектов, превращающих, казалось бы, простое и ясное в неимоверно противоречивое, что это привело к очень сильному падению первоначального энтузиазму и к необходимости определиться хотя бы с его основаниями. Европейские страны признали вдруг крах своей политики «мультикультурализма», страны Востока, а с ними и Россия, засомневались в такой уж неизбежности своего приближения к европейским стандартам. Национальное самосознание заговорило на совершенно новом языке. Былая приветливость отношений вдруг оказалась тонкой ширмой, скрывающей грубые политико-экономические интересы. И вот в последнее время нарастающим стало новое опасное умонастроение требования приближающейся войны как первейшего очистительного блага для современного мира. Чего же стоил диалог культур? Неужели он оказался мифом?

В высшей степени интересным является доклад, представленный на последних Лихачёвских чтениях главным их организатором, ректором СПбГУП членом-корреспондентом РАН, профессором А.С. Запесоцким. По сути в этом докладе он переосмысливает саму гуманистическую идею диалога между культурами, которая лежит в основе всей идеи Чтений и является особо близкой пози- ции Д.С. Лихачёва. Размышляя о евразийской концепции развития России, неприемлемой для Лихачёва, видящего место России исключительно в ряду европейских стран, и сравнивая позиции теоретических противников в этом вопросе - Д.С. Лихачёва и Л.Н. Гумилева - А.С. Запесоцкий приходит к выводу об очень сильном и очевидном европоцентризме позиции Лихачёва, обращает внимание на признание Лихачёвым определённого превосходства европейской культуры над другими - уже хотя бы в силу её христианских оснований: «Д.С. Лихачёв прямо ставит христианство нравственно выше всех остальных религий как единственную из них, “в которой Бог - личность", способная понимать и страдать. Второй аспект европейской культуры, утверждающий в глазах Лихачёва её превосходство, универсализм, то есть восприимчивость к другим культурам. И еще один “европейский принцип”, на котором как на “всечеловеческом" настаивает академик Лихачёв, - это принцип свободы, и прежде всего свободы внутренней, свободы творческого самовыражения личности» ${ }^{3}$. Причем автор доклада обращает внимание на то, что подобная оценка является весьма основательной и веской. Он приводит и слова А.А.Зиновьева на ту же тему: «Западноевропейская культура сложилась как культура высочайшего интеллектуального, морального и профессионального уровня, причем с утонченным и чрезвычайно строгим эстетическим вкусом. Создатели её были выдающиеся таланты и гении. Эта культура сыграла беспрецедентную роль в просвещении и нравственном совершенствовании человечества. Она аристократична и элитарна в том смысле, что не опускалась добровольно или по принуждению до плебейского уровня масс, а, наоборот, возвышала массу до высочайшего интеллектуального, морального и эстетического уровня своего времени» ${ }^{4}$. Если подобная оценка имеет отношение к действительности, то она не может быть однозначно отринута. И тем не менее противоположная позиция, настаивающая на различии,

\footnotetext{
3 Запесоцкий А.С. Россия на евразийском пространстве. Размышления о прошлом и будущем (К вопросу о современной теории и практике евразийства) // XIV Международные Лихачёвские научные чтения. 15-16 мая 2014 г. СПб.: СПбГУП, 2014. С. 63. (Работа Д.С. Лихачёва цит. по: Лихачёв Д.С. Три основы европейской культуры и русский исторический опыт // Лихачёв Д.С. Избр. труды по русской и мировой культуре. СПб.: СПбГУП, 2006. С. 365.)

4 Там же. (Работа А.А. Зиновьева цит. по: Зиновьев А.А. Запад. Феномен западнизма. М.: Центрполиграф, 1995. С. 315.)
} 
на особом пути, а также на возможной неприемлемости европейского образа жизни на русской почве и на почве других стран, где их применение ведет к культурному насилию, к механическому уничтожению самобытности, к порче и загниванию, и, как следствие, к активному протесту, неприятию этого вторжения, также оказывается существенной. В результате чего докладчик приходит к выводу не о том, что обе позиции неправильны, и не о том, что нужно выбрать одну из них, но о том, что обе они верны: «Кто прав: Гумилев или Лихачёв? Сегодня получается, что правы оба вместе. И ни один сам по себе» ${ }^{5}$. Признание этой парадоксальной одновременности указывает на глубину и объемность проблемы, неразрешимой в одной плоскости.

\section{Диалог культур как понятие новоевропейского мыслительного проекта}

И вот в этом контексте нужно отметить, что практически все докладчики, переходящие к обобщающим выводам по проблеме диалога культур, соглашаются с тем, что в данном случае речь идет о доминанте ценности, выработанной западноевропейским мировоззрением. Сам гуманистический идеал признания ценности любой личности - это идеал западного индивидуализма, который смог сложиться только в определённых специфических исторических условиях и имеет своей оборотной стороной многие весьма опасные качества данного типа мировоззрения, ведущие в современном мире к катастрофическим последствия ${ }^{6}$. Также и установка на необходимость ведения диалога выходит из недр диалектики абсолютного субъекта в немецком идеализме, где первейшим участником

\footnotetext{
5 Там же.

6 Ср.: «Этот идеал был сформулирован в определённой форме и в определённое время. Это произошло в эпоху европейского Возрождения. Первые гуманисты при этом опирались на некоторые традиции античной философии. Гуманизм как идеал предполагает ценность индивидуальной человеческой жизни, признание достоинства и свободы человека, возможность и необходимость его самосовершенствования. Иными словами, это вера в человека и его возможности, то есть это светский идеал... Однако изначально в самом идеале гуманизма были заложены возможности такого его понимания, которые при своей реализации выводили за его пределы, то есть вступали в противоречие с той идейной позицией, из которой они, казалось бы, вырастали. В наше время это стало особенно ясно». (Лекторский В.А. Гуманизм в контексте диалога культур // XIV Международные Лихачёвские научные чтения 15-16 мая 2014 г. СПб.: СПбГУП, 2014. С. 93-94.)
}

диалога, вступающим во взаимодействие с субъектом, становится его собственное инобытие, то, что полагается в качестве объекта. Без этого «иного» оказывается невозможным самопознание субъекта, который может узнать себя, лишь определяя себя и ставя себе границы. Таким образом оказывается, что то, что полагается в качестве объекта, не пассивно, но сообщает мне нечто для самопознания. Объект приобретает черты Другого субъекта, субъекта, с которым я вступаю в диалог. Но в любом случае, в этой перспективе он остается моим собственным Другим, и в то же время приобретает независимость и пугающую чуждость и непостижимость для меня. Причем интересно, что истоки подобного погружения в диалектику Я и Другого, доводящую в конце концов мысль до субъективизма, граничащего временами с солипсизмом, обращающего мир в симуляцию и иллюзию, безосновную и парадоксальную, можно связать также с отмеченными Д.С. Лихачёвым христианскими основаниями западноевропейской культуры. Отказываясь от закона во имя Благодати, христианство пересосредоточивает внимание на собственном внутреннем порыве человека, но его глубинном общении с божеством, интернализирует религиозный опыт, возлагает на человека ответственность за принятие решений, за перипетии внутренних переживаний. То, что прежде определялось законом или действием сверхъестественных сил извне, теперь становится собственной виной человека7. Он теперь не столько может, сколько вынужден доверять своему собственному опыту. Он уповает на Благодать и чает спасения, в то время как Закону можно было следовать определённо и непреложно. Он теряет надежность оснований во вне и вынужден теперь искать основания внутри. Это и есть порыв к совершенно новой степени свободы. Но

\footnotetext{
Ср.: «Разница между тем и этим, конечно, есть, и состоит она в том, что грех - это состояние падшей воли, болезнь человеческой души, тогда как осквернение - автоматическое следствие определённого поступка; оно принадлежит к миру внешних событий и действует с тем же полнейшим безразличием к мотиву поступка, с каким действует, скажем, тифозная вошь. Строго говоря, архаическое чувство вины становится чувством греховности только в результате "интернализации” сознания (термин Кардинера) - феномена, который появляется позднее и, вероятно, только в эллинистическом мире, причем становится распространенным спустя долгое время после того, как гражданское законодательство начало признавать важность мотива». (Доддс Э. Греки и иррациональное. СПб., 2000. С. 61-62. - Ссылка на: Kardiner. The Psychological Frontiers of Society. P. 439.)
} 


\section{Философия и культура 6(90) • 2015}

это же и путь в бездну без надежды где-либо остановиться. Потому что свобода в чистом виде есть негативность. Почему создатель философской антропологии М. Шелер, рассуждая о специфике человека как человека в своем знаковой работе «Положение человека в космосе» (1928) определяет человеческий дух как негативность - способность сказать «нет» миру․․ При этом для того, чтобы добиться для человека действительной моральной ответственности и свободы, ему приходится постулировать атеистическую позицию: «Богу нельзя существовать и Бог не должен существовать во имя ответственности, свободы, предназначения, во имя смысла бытия человека... “Личность”, может существовать только в механически или, но крайней мере, в нетелеологически построенном мире. В мире, который Божество сотворило по своему плану или в котором оно располагает в каком-либо смысле будущим, - в этом мире человек как нравственное существо, как личность уничтожен» ${ }^{9}$. И вот этот вывод, как мы могли увидеть, является не противоречием, но определённым путём очень последовательного развития религиозной христианской мысли. Не случайно современный итальянский философ Дж. Ваттимо полагает, что секуляризация является настоящей целью христианского проекта ${ }^{10}$. Безусловно можно бы было указать и на другие возможности развития христианской религиозной идеи и обвинить западноевропейскую мысль в извращении её смысла, как это и делают многие отечественные философы еще с XIX в. Однако идея гуманизма тесно связана именно с этой линией, как и идея диалога и признания права другого, иного, на свою чуждость.

Нужно признать, что в обычной ситуации любой человек и любое общество весьма склонно к ксенофобии. Разделение на «своих» и «чужих» является архетипическим, при этом «своё» признается по умолчанию единственно правильным и несомненным, «чужое» же - злым, вражеским, ненормальным, безобразным. Великие свершения человеческого самосознания во времена, названные немецким мыслителем К.Ясперсом «осевым временем» связаны именно с тем, что впервые этот ар-

8 Шелер М. Положение человека в космосе / Пер. с нем. А.Ф. Филиппова // Шелер М. Избр. произв. М., 1994. С. 161-165.

9 Шелер М. Человек и история / Пер. с нем. А.Н. Малинкина // Шелер М. Избр. произв. М., 1994. С. 94.

10 См.: Ваттимо Дж. После христианства / Пер. с ит. Д.В. Новикова. М.: Три квадрата, 2007. С. 34, 40. хетип был вынужден сдать свои позиции. Человек впервые открылся, или был вынужден определёнными обстоятельствами своей жизни открыться к общению и воспринять, что существуют разные вполне достойные и приемлемые типы поведения. Во многих случаях такое открытие бывает связано с тем, что свой собственный тип поведения даёт трещины и перестает удовлетворять, или же является принципиально недостаточным. И всё же такого уровня неудовлетворённости и самокритики, с каким столкнулась европейская мысль конца XIX в. не знала ни одна эпоха. Именно это время сформировало основы того, что можно назвать «гуманитарным знанием». Это произошло в Европе и произошло потому, что европейские ценности стали приходить в противоречие сами с собой. Что благие порывы терпели крах, что наилучшие достижения науки и техники приводили к катастрофическим результатам, что порыв к политическому освобождению рождал террор, а экономическая свобода приводила к тяжелейшим формам эксплуатации. Лучшее и худшее непрерывно соседствовали друг с другом. Та же диалектика наблюдается и в гуманитарной мысли с её идеей диалога между субъектами. Диалог, безусловно, ценен тем, что даёт другому право быть собой и сообщать о себе. Даёт право участникам диалога влиять друг на друга, понимать друг друга. Он устраняет ксенофобию. Но - как уже было сказано, в обычной ситуации любой человек и любое общество склонны к ксенофобии. Кроме ситуации крайнего кризиса и сомнения в себе. Любая уверенная жизнь утверждает себя и только себя и не хочет ни с кем говорить. И вот мы настаиваем на диалоге. Мы даем право говорить всем. С какой позиции может быть дано это право? Лишь с позиции безусловно превосходящего. Потому что никто больше этого диалога не предполагал. И вот это требование навязывается извне, и тот, кто ему не следует, объявляется негуманистичным, недемократичным, нетолерантным, словом, в высшей степени дурным, чуждым, безобразным и злым. Итак, то, что должно было послужить поиску новых путей развития для страдающей противоречиями западноевропейской культуры, то, что должно было преодолеть ксенофобию и дать право всем на свое уникальное многообразие - то же самое ведет к уничтожению многообразия, навязыванию западноевропейского типа мышления как единственно возможного и к наиболее радикальной ксенофобии. Причём интересно, что этого потрясающего превосходства европейская культура достигает именно в тот момент, 
когда более всего оказывается, на уровне самосознания, неуверенной в себе. Неуверенность и недостаточность составляют как бы путь к поглощению всего и утверждению единственно своего идеала поведения. Неудивительно, что подобная ситуация породила психоаналитическую подозрительность и стремление к выявлению бессознательного. Причем в данном случае можно не касаться даже весьма и весьма существенных процессов обретения западным миром политического и экономического влияния. Одной парадоксальной структуры мышления оказывается достаточным для развертывания этого подавляющего господства по всему миру, все остальное следует уже из нее.

И вот этот-то идеал диалога, внимания к другим, плюралистичности и многогранности предлагается проводить последовательно в процессе взаимодействия культур, потому что, на самом деле, лучше, чем такая форма взаимодействия, придумать что-либо сложно. Все остальное ведет к ксенофобии и смертоубийству. Беда в том, что и подобный вариант своей обратной стороной, как мы видели, также имеет ксенофобию и смертоубийство. А если и не смертоубийство, то по крайней мере точно - уничтожение самобытности. Между тем как идеалом этого самого диалогического типа поведения является как раз её сохранение и поддержание.

\section{Спор философских позиций по отношению к диалогу культур}

Чтобы проследить перипетии и сложности этой проблемы, разберем только два подхода, из представленных в рамках Лихачёвских чтений, выявляя, насколько при различии начальных позиций они оказываются сходными, и при сходствах выводов тем не менее различными. Во-первых, обратимся к концепции академика А.А. Гусейнова, в течение уже нескольких лет развивающего свою мысль в рамках Лихачёвских чтений. А.А. Гусейнов проводит в своих размышлениях осознанно европоцентристскую позицию, полагая такие ценности как гуманизм, диалогичность и толерантность «этическим достижением новоевропейской культуры, её вкладом в общечеловеческую нравственность» ${ }^{11}$. В докладе, представленном на Лихачёвских чте-

11 Гусейнов А.А. Толерантность и диалог культур // Диалог культур и партнерство цивилизаций. IX Международные научные Лихачёвские чтения 14-15 мая 2009 г. СПб., 2009. С. 66. ниях 2010 г. и озаглавленном «Как возможна глобальная общность людей?», он высказывает интересную идею о том, что глобальная общность возможна только как общность транскультурная, и той же мысли вторит в своем докладе на последних Чтениях: «Культурное многообразие предполагает некую транскультурную точку отсчета, которая является нейтральной по отношению ко всем встречающимся и вообще возможным культурам и более высокой, чем каждая из них в отдельности и все они вместе» ${ }^{12}$. А.А. Гусейнов исходит здесь из соображений морали, из этической необходимости уважения человеком человека, которое должно быть распространено абсолютно на всех и не признавать различия между своим и чужим. Он утверждает, что мир «един и принадлежит всем обитающим в нем людям» ${ }^{13}$. И потому они владеют им всем и не ограничены своей территорией. Его порыв - доказать или даже показать необходимость следования принципам толерантности. Он предлагает, опираясь на слова современного социолога 3. Баумана (автора, в том числе, книги с показательным названием: «Текучая современность»(2000)), заменить в отношении местожительства человека метафору почвы метафорой якоря и уподобить современного человека скорее «путешественнику или моряку, бороздящему моря и океаны», чем «привязанному к полю крестьянину ${ }^{14}$, что позволит смягчить различия, сгладить границы между чуждыми друг другу людьми и культурами. Но интересно, насколько метафора Баумана соответствует даваемой последним весьма критической аналитической характеристике проблем и бед современного постмодернистского общества как текучего, ненадежного, зыбкого. В то же время она отсылает к другому описанию западноевропейской культуры во всей её хищнической, захватнической сути, данному К. Шмиттом в работе «Земля и море». Здесь морской взгляд, который до высшей степени совершенства довела Англия Нового времени в осуществлении своей колониальной политики, сравнивается со взглядом пирата, для которого вся видимая суша есть просто «незахваченная

\footnotetext{
12 Гусейнов А.А. «Свои» и «чужие» в глобализирующемся мире // XIV Международные Лихачёвские научные чтения 15-16 мая 2014 г. СПб.: СПбГУП, 2014. С. 55.

13 Там же. С. 56.

14 Там же. С. 57.
} 


\section{Философия и культура 6(90) • 2015}

территория» ${ }^{15}$. И в то же время это единственное условие для поддержания взаимоуважительной морали! Здесь мы снова сталкиваемся все с той же двоякостью и внутренней конфликтностью, о которой уже шла речь в отношении принципов западноевропейской культуры.

По сути, А.А. Гусейнов следует последовательной рационалистической просветительской линии, приводящей его также и к признанию необходимости секуляризации морали от религии ${ }^{16}$ как условия поддержания действительно взаимоуважительного общения. Но это означает, что уже, по крайней мере, свою самобытную веру человек глобального сообщества не должен принимать всерьез. Чтобы быть способным к диалогу, он должен заранее перейти на релятивистскую позицию и стать атеистичным, секуляризировать мораль. Но не значит ли это - лишить её живого источника энергии и впасть в ту же болезнь, которой страдает западноевропейская культура? Занимая такую позицию можно подходить к различным культурам только с эстетической меркой, но именно эту мерку, фактически, предлагает также и Д.С. Лихачёв, полагая, что «утрата любого элемента культурного наследия является невосполнимой потерей и ведет к духовному обеднению всей человеческой цивилизации» ${ }^{17}$. Христианин не желает хранить языческие идолы, а исламист - изображения Будды, потому, что для него они есть символы лжи и заблуждения, пока жива его вера. Кто же сохранит их все в музее, не поклоняясь ни одному из них, как не эстет, желающий сохранить все в качестве напоминаний, сувениров, или ученый-гуманитарий, исследующий все возможные культуры, будучи охваченным чувством постмодернистской запоздалости? Чужое становится интересным, когда свое обращается в ничто. Этот нигилистический порыв порождает страсть к музею, архиву, сбору материалов и фактов, а также к объективному ис-

15 Шмитт К. Земля и море / Пер. с нем. К. Лощевского и Ю. Коринца // Шмитт К. Номос земли в праве народов јus publicum europaeum. СПб.: Владимир Даль, 2008. С. 630.

16 Гусейнов А.А. Диалог культур: возможности и пределы // Диалог культур и партнерство цивилизаций. VIII Международные научные Лихачёвские чтения 22-23 мая 2008 г. СПб., 2008. C. 69.

17 Цит. по: Запесоцкий А.С. Проблематика диалога культур в научном и нравственном наследии академика Д.С. Лихачёва // Диалог культур и партнерство цивилизаций: становление глобальной культуры. Х Международные научные Лихачёвские чтения 13-14 мая 2010 г. СПб., 2010. С. 76. следованию, которое и составляет суть сохранения культуры. В этой связи можно вспомнить любопытное высказывание словенского психоаналитика-парадоксалиста С. Жижека, насмехающегося над распространившейся в последнее время формулировкой относительно, в частности, принадлежности к религии: «По-настоящему я не верю, это лишь часть моей культуры». Действительно, очень часто можно слышать о принадлежности к той или иной конфессии только на том основании, что это «традиция». А это уже означает, что как таковой веры подобная принадлежность за собой не имеет. Вера в необходимость сохранения традиции заменяет здесь отсутствующую веру в Бога. Делая вывод, Жижек пишет: «ККультурой” называется все то, что мы практикуем, по-настоящему не веря во все это, "не принимая всерьез" ${ }^{18}$.

С этой же проблемой сталкивается и другой докладчик, главный научный сотрудник института искусствознания РАН, профессор Н.А. Хренов. В своем докладе он очень метко и точно выделяет тупики и противоречия западноевропейской культуры, производящей современную глобализацию мирового пространства. Он в высшей степени критически оценивает то, что А.А. Гусейнову представляется величайшим достижением модерна, и пытается противостоять именно той тенденции, которую можно назвать «просветительской»: «Немецкий философ Ю. Хабермас эпоху Просвещения назвал эпохой модерна. Это обобщенный образ того, что можно было бы назвать проектом пересоздания фундаментальных основ жизни. Следствием модерна оказались революции Нового и Новейшего времени. Возникая, модерн надолго отсрочил открытие в науке смысла культуры, что не удивительно: ведь просветители (они же носители идеи модерна) исходили из того, что Кант называл “чистым разумом", а значит, из логики. Таким образом, уже в XVIII в. возникла некая система, выходящая за пределы культуры, становление которой развертывалось на протяжении столетий. Прогресс как ключевое слово модерна исходил не из традиции. Просветители были убеждены в том, что никаких образцов в прошлом больше существовать не будет. Они исходили не из культуры, а из наднациональных, надисторических, надэтнических и надконфессиональных стихий, из которых и образовалось то, что будут называть идео-

18 Жижек С. Кукла и карлик: христианство между ересью и бунтом / Пер. с англ. С. Кастальского. М., 2009. С. 14. 
логией. Перечеркивая прошлое, носители модерна переоценивали значимость будущего, о чем свидетельствовали их утопические проекты радикального переустройства общества» ${ }^{19}$.

В этом отрицании прошлого, отрицании традиции, в уравнивании всего и вся перед лицом единой рациональности, ему видится серьезная утрата. Но интересно обратить внимание на двоякость проблемы и в данном случае. Ещё К. Маркс описывал это уничтожение границ и обезличивание, полагая его следствием деятельности буржуазии, бессовестной и наглой, однако видя в этом и её чрезвычайную революционную роль, раскрывающую дорогу к принципиально новому обществу. Вот как Маркс и Энгельс трактует становление буржуазного порядка: «На смену старой местной и национальной замкнутости и существованию за счет продуктов собственного производства приходит всесторонняя связь и всесторонняя зависимость наций друг от друга. Это в равной мере относится как к материальному, так и к духовному производству. Плоды духовной деятельности отдельных наций становятся общим достоянием. Национальная односторонность и ограниченность становятся все более и более невозможными, и из множества национальных и местных литератур образуется одна всемирная литература» ${ }^{20}$. Итак снова то же, что является чудовищным и убийственным для всего ценного и человеческого, является также и условием выхода на принципиально новый уровень. Привязанность к старым традициям, к старым ценностям, закабаляет человека, она реакционна и удерживает его в невидимых путах эксплуатации, которые только буржуазная наглость делает видимыми - а потому, наконец, уничтожимыми. Потому, конечно, Маркс может с полным правом сказать - к чему явно и апеллирует в своей критике Н.А. Хренов, что «социальная революция XIX века может черпать свою поэзию только из будущего, а не из прошлого» ${ }^{21}$.

И вот этот именно модернистский порыв к свободе, нацеленность на будущее, сметение прошлого с лица земли, настаивая на уничтожении

\footnotetext{
19 Хренов Н.А. Судьба культуры в ситуации войны как формы контакта между цивилизациями // XIV Международные Лихачёвские научные чтения 15-16 мая 2014 г. СПб.: СПбГУП, 2014. С. 177.

20 Маркс К., Энгельс Ф. Манифест коммунистической партии. М.: Common place, 2013. С. 33.

${ }_{21}$ Маркс К. 18 брюмера Луи Бонапарта // Маркс К., Энгельс Ф. Соч. Изд. 2-е. Т. 8. С. 122.
}

самобытности традиций, на стирании культурных различий, в итоге порождает напряжение и оказывается источником конфликтов. Спасительной в этом контексте Н.А. Хренову представляется гуманитарная идея культуры - но эта идея также порождена и сформулирована европейской мыслью в порыве углубления в свою рефлексию. Докладчик полагает однако, что рефлексия становится культурологической и образует внутреннее противоядие против разрушительного порыва, заставляя «заново прочитать историю под углом зрения возникновения и распространения того, что называют идеей культуры» ${ }^{22}$. Но что же будет культурой вне поддерживающих её источников питания? А поддерживать её может только крайняя отличенность и неуважительное принятие «всерьёз» своих ценностей и традиций. И тогда она не входит в общее поле культуры и не способна к вступлению в диалог.

Доклад Н.А. Хренова посвящён очень любопытной теме, а именно теме войны. И цель его обнаружить эту конфликтогенную склонность в недрах культуры модерна, породившего череду мировых войн и революций. И вот, возвращаясь к началу нашего рассуждения, мы можем вспомнить уже отмеченную нарастающую тягу к военному напряжению в современном мире, крах надежд на дружбу и взаимопониманию в том простом виде, в каком они казались возможными некоторое время назад. Неслучайно и мысли о диалоге культур оказываются все более усложняющимися и всё более входящими в противоречие между собою. Это свидетельствует о большой напряжённости ситуации.

\section{Диалог и конфликт}

И вот здесь, вероятно, мы наталкиваемся на проблему, которая неслучайно стала отдельной темой одной из секций Лихачёвских чтений, а именно, на проблему соотношения «своего» и «чужого» в глобальном пространстве. Как уже говорилось, само по себе деление является архетипическим. Притом, его можно назвать очень важным, значимым: оно обеспечивает самобытность, различенность, множественность, и в то же время упорядочивает множественное, разграничивает пространство,

22 Хренов Н.А. Судьба культуры в ситуации войны как формы контакта между цивилизациями // XIV Международные Лихачёвские научные чтения 15-16 мая 2014 г. СПб.: СПбГУП, 2014. С. 177. 


\section{Философия и культура 6(90) • 2015}

распределяет территории, привносит различие и порядок. Его именно можно назвать истоком «цветущей сложности» культуры, о которой говорил русский философ К.Н. Леонтьев, но оно же является и причиной раздоров и войн.

И в этом контексте весьма неслучайны слова Гегеля из «Философии права», цитируемые Н.А. Хреновым: «Высокое значение войны состоит в том, что благодаря ей... сохраняется нравственное здоровье народов, его безразличие к застыванию конечных определённостей; подобно тому, как движение ветров не даёт озеру загнивать, что с ним непременно случилось бы при продолжительном безветрии, так и война предохраняет народы от гниения, которое непременно явилось бы следствием продолжительного, а тем более вечного мира» ${ }^{23}$. Подобное же высказывание о войне мы можем найти и у Канта: «Сама война, если она ведётся в соответствии с установленным порядком и с соблюдением гражданских прав, таит в себе нечто возвышенное и делает образ мыслей народа, который ведёт её таким образом, тем возвышеннее, чем большим опасностям он подвергался, сумев мужественно устоять; напротив, длительный мир способствует обычно господству торгового духа, а с ним и низкого корыстолюбия, трусости и изнеженности и принижает образ мыслей народа» ${ }^{24}$, причем интересно то, что здесь война связывается с морально возвышающим человека эстетическим чувством. И конечно высочайшую степень рефлексии являет здесь интерпретатор гегелевской мысли А.Кожев, на идеи которого опирались впоследствии французские философские радикалы в своей тотальной критике современного общества: «Только война “не на жизнь, а на смерть” утверждает историческую свободу и свободную историчность Человека. Человек является историчным лишь в той мере, в какой он активно участвует в жизни Государства, а подобное участие приходит к своей кульминации тогда, когда Человек участвует в чисто политической войне, связанной с риском для жизни. Другими словами, человек является подлинно историчным и человечным лишь в той мере, в какой он является воином, по крайней мере

23 Там же. С. 171. (Цит. по: Гегель Г.В.Ф. Соч. М.; Л., 1934. Т. 7 : Философия права. С. 344).

24 Кант И. Критика способности суждения // Кант И. Соч. в 8 т. Т. V. М., 1994. С. 101-102. потенциально» ${ }^{25}$. И опять же обнаруживаем двоякую тенденцию в европейской мысли - с одной стороны к вот такому прославлению войны, а с другой - к пацифизму, отрицанию войны, обнаружению в ней ненужной жестокости, к страху перед войной и нежеланию войны, которое прямым образом связано с ростом индивидуализма и с признанием ценности любой человеческой жизни. Индивидуалист не хочет войны, боится войны и не знает, за что ему умирать, поскольку выше всего он ценит самого себя - но именно он и только он может на «безопасном расстоянии» эстетической рефлексии о возвышенном оценить её важность в становлении человека. Оценить важность борьбы, важность конфликта, противоречия, травмы которых он сам так старается избежать. Вот откуда и гегелевская мысль о постисторичности: только выйдя за пределы истории, можно оценить борьбу как суть истории, вобрать её в себя, воспользоваться ею, и в то же время её избежать. Но если мы всетаки не можем выйти за пределы истории, что же нам остается делать?

Противоречие между «своим» и «чужим», упорядочивающее и очевидное для любого замкнутого традиционного сознания, где индивидуальное подчинено коллективной, но все же локальной идее, и где никто не задумывается пожертвовать за эту идею жизнью, становится в высшей степени неочевидным для сознания индивидуализированного рефлексией. Последнее мыслит себя предельно уникальным, но мыслит также и равенство всего перед лицом этой уникальности. Как только любой другой человек или другая культура, другая вещь, включая природу в целом, приобретает статус настоящего Другого, она наделяется субъективностью и правом на ведение диалога. Она перестает быть чужим врагом, с которым следует бороться «не на жизнь, а на смерть» просто ради того, что это враг, т.е. за идею. Эта идея, определяющая смысл и суть любой культуры, идея, ради которой можно было жить и за которую умирать, она была тем, что можно назвать метафизической, религиозной идеей, идеей Бога - того Бога, который является Богом верящего в него народа. Её вытеснение и замена отношением равных субъектов приводит к секуляризации и гомогенизации общества. Больше нет чужого, больше нет противника, все равны и все оказывается смешанным, беспорядочным.

25 Кожев А. Идея смерти в философии Гегеля / Пер. с франц. И. Фомина. М.: Логос, Прогресс-Традиция, 1998. С. 178. 
Никто больше не знает, за что он борется, а если борется, то это кажется безумным и негуманным. И не только кажется, а действительно является таковым. И вот эта-то самая негуманность, этот страх, этот ужас, ужас смерти, оказываются единственным «чужим», что еще задаёт границы гомогенному транскультурному пространству. Установив идею равенства людей, индивидуалистическое сознание вытеснило идею Бога за пределы мира, секуляризировала её и превратила в страх перед Ничто, ради которого только и происходит вся дальнейшая борьба. Если нет метафизической идеи за пределами мира, а Бог есть проекция человеческой субъективности, то войны и революции, поддерживающие порядок различенности в мире, происходят исключительно ради самих себя в качестве самоцели. Травма и принципиальная разорванность субъективности показывает в них себя в чистом виде. Потому «чужим» врагом в таких условиях может оказаться все, что угодно, и требуется только умелый идеолог, чтобы на такого врага показать - чем и обусловлено то, что фашистские идеи до сих пор пользуются успехом. Но в условиях отсутствия метафизической подоплеки все эти идеологии оказываются внутричеловеческими, условными, ненадежными, а потому очень шаткими и никогда не завладевающими надолго.

Исходя из этих посылок, можно сделать вывод, что диалог, как и противостояние, являются разными способами взаимодействия различенных субъектов в поле гомогенизирующей рефлексии. Вне этого поля взаимодействие происходит по принципам войны «своего» и «чужого», где каждый исходит из своей системы отсчета. И это не предполагает взаимодействия - только люди сталкиваются между собой в смертельной схватке, но не культуры в мировоззренческом плане. Если они сталкиваются в мировоззренческом плане - они уже перешли в единое поле рефлексии, где и диалог и противостояние - это разные формы взаимодействия друг с другом.

И вот теперь вопросом является, что же действеннее в случае конфликта: сохранение самобытности и принятие своего локального поля действия "всерьез», то есть отказ от уважительной транскультурной позиции, который может не дать заметить, как «враг» уже внедрился невидимо вглубь твоего культурного пространства и разъедает его основания, - или же попытка приступить к взаимодействию на равных, поскольку тот, кто понимает, всегда сильнее того, кто не понимает, а диалог предполагает взаимные попытки друг друга понять? Второй подход представляет собой отказ от части своей самобытности, но первый чреват физическим устранением из глобализированного мира. В любом случае, при осуществлении такого взаимодействия мирным путем на сцену выходит уже не ученый-этнограф, описывающий антропологические различия, и не музейный работник, собирающий культурные ценности, и даже не интернационалист-гуманист, призывающий всех к любви, дружбе и всеобщему объединению, но скорее конфликтолог-практик, не столько устраняющий и разрешающий конфликты между различенными, сколько способный ловко замечать их основания, регулировать их интенсивность и манипулировать ими, выстраивая подспудно выгодную его стороне диспозицию.

\section{Список литературы:}

1. Ваттимо Дж. После христианства / Пер. с ит. Д.В. Новикова. М.: Три квадрата, 2007.

2. Гусейнов A.A. «Свои» и «чужие» в глобализирующемся мире // XIV Международные Лихачёвские научные чтения. 15-16 мая 2014 г. СПб.: СПбГУП, 2014.

3. Гусейнов А.А. Диалог культур: возможности и пределы // Диалог культур и партнерство цивилизаций. VIII Международные научные Лихачёвские чтения. 22-23 мая 2008 г. СПб., 2008.

4. Гусейнов А.А. Толерантность и диалог культур // Диалог культур и партнерство цивилизаций. IX Международные научные Лихачёвские чтения. 14-15 мая 2009 г. СПб., 2009.

5. Доддс Э. Греки и иррациональное. СПб., 2000.

6. Жижек С. Кукла и карлик: христианство между ересью и бунтом / Пер. с англ. С. Кастальского. М., 2009.

7. Запесоцкий А.С. Проблематика диалога культур в научном и нравственном наследии академика Д.С. Лихачёва // Диалог культур и партнерство цивилизаций: становление глобальной культуры. Х Международные научные Лихачёвские чтения. 13-14 мая 2010 г. СПб., 2010.

8. Запесоцкий А.С. Россия на евразийском пространстве. Размышления о прошлом и будущем (К вопросу о современной теории и практике евразийства) // XIV Международные Лихачёвские научные чтения. 15-16 мая 2014 г. СПб.: СПбГУП, 2014.

9. К Кант И. Критика способности суждения // Кант И. Соч. в 8 т. М., 1994. Т. V.

10. Кожев А. Идея смерти в философии Гегеля / Пер. с франц. И. Фомина. М.: Логос, Прогресс-Традиция, 1998. 


\section{Философия и культура 6(90) • 2015}

11. Лекторский B.A. Гуманизм в контексте диалога культур // XIV Международные Лихачёвские научные чтения. 15-16 мая 2014 г. СПб.: СПбГУП, 2014.

12. Маркс К. 18 брюмера Луи Бонапарта // Маркс К., Энгельс Ф. Соч. Изд. 2-е. Т. 8.

13. Маркс К., Энгельс Ф. Манифест коммунистической партии. М.: Common place, 2013.

14. Ницше Ф. К генеалогии морали / Пер. с нем. К.А. Свасьяна // Ницше Ф. Соч. в 2 т. Т. 2. М., 1990.

15. Хренов Н.А. Судьба культуры в ситуации войны как формы контакта между цивилизациями // XIV Международные Лихачёвские научные чтения. 15-16 мая 2014 г. СПб.: СПбГУП, 2014.

16. Шелер М. Положение человека в космосе / Пер. с нем. А.Ф. Филиппова // Шелер М. Избр. произв. М., 1994.

17. Шелер М. Человек и история / Пер. с нем. А.Н. Малинкина // Шелер М. Избр. произв. М., 1994.

18. Шмитт К. Земля и море / Пер. с нем. К. Лощевского и Ю. Коринца // Шмитт К. Номос земли в праве народов јus publicum europaeum. СПб.: Владимир Даль, 2008.

\section{References (transliterated):}

1. Vattimo Dzh. Posle khristianstva / Per.s it. D.V. Novikova. M.: Tri kvadrata, 2007.

2. Guseinov A.A. «Svoi» $\mathrm{i}$ «chuzhie» v globaliziruyushchemsya mire // XIV Mezhdunarodnye Likhachevskie nauchnye chteniya. 15-16 maya 2014 g. SPb.: SPbGUP, 2014.

3. Guseinov A.A. Dialog kul'tur: vozmozhnosti i predely // Dialog kul'tur i partnerstvo tsivilizatsii. VIII Mezhdunarodnye nauchnye Likhachevskie chteniya. 22-23 maya 2008 g. SPb., 2008.

4. Guseinov A.A. Tolerantnost' i dialog kul'tur // Dialog kul'tur i partnerstvo tsivilizatsii. IX Mezhdunarodnye nauchnye Likhachevskie chteniya. 14-15 maya 2009 g. SPb., 2009.

5. Dodds E. Greki i irratsional'noe. SPb., 2000.

6. Zhizhek S. Kukla i karlik: khristianstvo mezhdu eres'yu i buntom / Per. s angl. S. Kastal'skogo. M., 2009.

7. Zapesotskii A.S. Problematika dialoga kul'tur v nauchnom i nravstvennom nasledii akademika D.S. Likhacheva // Dialog kul'tur i partnerstvo tsivilizatsii: stanovlenie global'noi kul'tury. X Mezhdunarodnye nauchnye Likhachevskie chteniya. 13-14 maya 2010 g. SPb., 2010.

8. Zapesotskii A.S. Rossiya na evraziiskom prostranstve. Razmyshleniya o proshlom i budushchem (K voprosu o sovremennoi teorii i praktike evraziistva) // XIV Mezhdunarodnye Likhachevskie nauchnye chteniya. 15-16 maya 2014 g. SPb.: SPbGUP, 2014.

9. Kant I. Kritika sposobnosti suzhdeniya // Kant I. Soch. v 8 t. T. V. M., 1994.

10. Kozhev A. Ideya smerti v filosofii Gegelya / Per. s frants. I. Fomina. M.: Logos, Progress-Traditsiya, 1998.

11. Lektorskii V.A. Gumanizm v kontekste dialoga kul'tur // XIV Mezhdunarodnye Likhachevskie nauchnye chteniya. 15-16 maya 2014 g. SPb.: SPbGUP, 2014.

12. Marks K. 18 bryumera Lui Bonaparta // Marks K., Engel's F. Soch. Izd. 2-e. T. 8.

13. Marks K., Engel's F. Manifest kommunisticheskoi partii. M.: Common place, 2013.

14. Nitsshe F. K genealogii morali / Per. s nem. K.A. Svas'yana // Nitsshe F. Soch. v 2 t. T. 2. M., 1990.

15. Khrenov N.A. Sud'ba kul'tury v situatsii voiny kak formy kontakta mezhdu tsivilizatsiyami // XIV Mezhdunarodnye Likhachevskie nauchnye chteniya. 15-16 maya 2014 g. SPb.: SPbGUP, 2014.

16. Sheler M. Polozhenie cheloveka v kosmose / Per. s nem. A.F. Filippova // Sheler M. Izbr. proizv. M., 1994.

17. Sheler M. Chelovek i istoriya / Per. s nem. A.N. Malinkina // Sheler M. Izbr. proizv. M., 1994.

18. Shmitt K. Zemlya i more / Per. s nem. K. Loshchevskogo i Yu. Korintsa // Shmitt K. Nomos zemli v prave narodov jus publicum europaeum. SPb.: Vladimir Dal', 2008. 